\title{
A 28 kDa major immunogen of Chlamydia psittaci shares identity with Mip proteins of Legionella spp. and Chlamydia trachomatis - cloning and characterization of the $\mathbf{C}$. psittaci mip-like gene
}

\author{
Daniel D. Rockey, Brian B. Chesebro, Robert A. Heinzen \\ and Ted Hackstadt
}

Author for correspondence: Daniel D. Rockey. Tel: +1 406363 9261. Fax: +1 4063639204.
e-mail: dan_rockey@nih.gov

Laboratory of Intracellular Parasites, Rocky Mountain Laboratories, National Institute of Allergy and Infectious Diseases, Hamilton, MT 59840, USA
Chlamydia psittaci strain guinea-pig inclusion conjunctivitis (GPIC) produces a self-limiting ocular infection of guinea-pigs, and this condition is a representative animal model of ocular chlamydial disease. Convalescent guinea-pigs, which are resistant to reinfection, produce antibodies to several elementary-body proteins, including an uncharacterized antigen of 28 kDa. Convalescent guinea-pig sera were used to identify, from a lambda expression library, two overlapping GPIC genomic clones that produced the $28 \mathrm{kDa}$ antigenic protein. Nucleotide sequence analysis revealed that the gene coding for the $28 \mathrm{kDa}$ protein was similar to the mip (macrophage infectivity potentiator) genes from Legionella pneumophila and Chlamydia trachomatis. The GPIC gene and its product were accordingly designated mip and Mip, respectively. Analysis of the regions flanking mip identified three tightly linked open reading frames coding for predicted products with sequence similarity to asparagine tRNA ligase (AspS), rRNA methylase (SpoU), and thioredoxin (TrXA). The arrangement of these genes in GPIC was aspS-mipspoU-trxA. Sequence analysis of PCR products produced using genomic DNA from an ovine abortion strain of C. psittaci and from C. trachomatis strain LGV434 demonstrated that the arrangement of mip, spoU and trxA is common among these chlamydiae.

Keywords: Chlamydia, Mip-like protein, chlamydial antigen, intracellular pathogen, intracellular survival

\section{INTRODUCTION}

The mip (macrophage infectivity potentiator) locus was first identified in Legionella pneumophila; it is associated with enhanced intracellular survival of legionellae in human macrophages and other cells (Cianciotto et al., 1989; Cianciotto \& Fields, 1992; Engleberg et al., 1989;

Abbreviations: EB, elementary body; FKBP, FK506-binding protein; GPIC, guinea-pig inclusion conjunctivitis; Mip/mip, macrophage infectivity potentiator protein/gene; LMip, Legionella pneumophila Mip protein; CtMip, Chlamydia trachomatis Mip protein; MOMP, major outer-membrane protein.

The GenBank accession number for the $C$. trachomatis $L 2$ partial spo $U$ and trxA sequences is L40369. That for the GPIC aspS, mip, spoU and trxA sequences is $L 39892$.
O'Connell et al., 1995). The L. pneumophila mip gene codes for a $24 \mathrm{kDa}$ protein (LMip) which is localized to the bacterial cell surface (Engleberg \& Eisenstein, 1991). Sequence comparisons and in vitro enzymic analyses have shown that LMip is structurally and functionally related to a family of peptidyl-prolyl cis/trans isomerases that bind the macrolide antibiotics FK506 and rapamycin, compounds that are therapeutically important as suppressors of $\mathrm{T}$ cell activation (Hacker \& Fischer, 1993). Although the Mip protein is associated with enhanced infectivity by the legionellae, its role in the infectious process is not understood.

A mip homologue from Chlamydia trachomatis was recently cloned and expressed in Escherichia coli (Lundemose et al., 1991, 1992). Subsequent reports have shown that the $C$. 


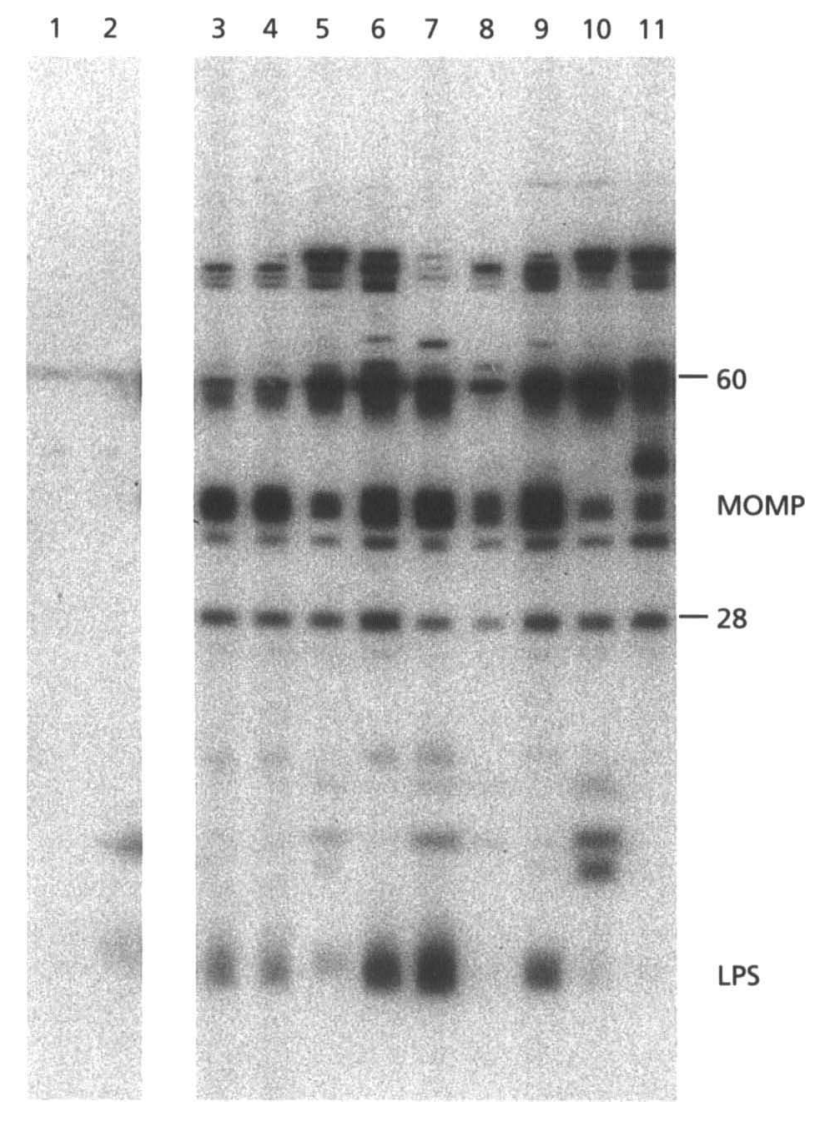

Fig. 1. Preparative immunoblot of GPIC EB probed with sera from individual convalescent guinea-pigs. Lanes: 1 and 2, sera from two naive guinea-pigs; $3-11$, sera from nine individual guinea-pigs that recovered from two serial challenges with GPIC. The positions of chlamydial lipopolysaccharide (LPS) and major outer-membrane protein (MOMP) are shown, and molecular masses are indicated in $\mathrm{kDa}$.

trachomatis Mip protein (CtMip) is a lipoprotein (Lundemose et al. 1993b), has enzymic activity characteristic of other FK506-binding proteins (FKBP) (Lundemose et al., 1993a), and may be exposed at the bacterial cell surface (Lundemose et al., 1992). While no direct role of CtMip in the chlamydial infectious process has been demonstrated, FK506 added between 0 and $16 \mathrm{~h}$ post-infection has been shown to interfere with the developmental cycle of $C$. trachomatis (Lundemose $e t$ al., 1993b).

Recent studies in our laboratory have focused on the immune response of guinea-pigs following ocular infection with Chlamydia psittaci (strain GPIC). The resulting clinical condition, called guinea-pig inclusion conjunctivitis, is used as an animal model for ocular chlamydial disease in humans (Monnickendam et al., 1980; Morrison et al., 1989; Watkins et al., 1986). Guineapigs that resolve a primary infection are resistant to reinfection (Rank et al., 1988) and these animals produce antibodies against a variety of chlamydial antigens (Batteiger \& Rank, 1987; Rank et al., 1990; Rockey et al.,
1995; Rockey \& Rosquist, 1994; Treharne \& Shallal, 1991). One of the chlamydial antigens consistently recognized by convalescent guinea-pig sera is an uncharacterized $28 \mathrm{kDa}$ protein. In this study, these convalescent sera were used to identify the gene coding for the $28 \mathrm{kDa}$ protein from an expression library of GPIC DNA. The predicted amino acid sequence encoded by this gene shared identity with the Mip-like family of FKBP. The nucleotide sequence of the GPIC mip-like gene and three surrounding open reading frames (ORFs) is presented, and a similar gene arrangement is shown to be present in another strain of $C$. psittaci and in $C$. trachomatis serovar L2.

\section{METHODS}

Bacterial strains, genomic library manipulation, and nucleotide sequence analysis. Chlamydia psittaci strain GPIC, ovine abortion strain B577, and C. trachomatis strain LGV-434 (serovar L2) were cultured in HeLa cells. Original stocks of chlamydiae were purchased from the American Type Culture Collection. Chlamydial culture and elementary body (EB) purification were performed using described methods (Rockey \& Rosquist, 1994; Caldwell et al., 1981). Construction, screening and manipulation of a GPIC genomic library were conducted using methods described by Rockey et al. (1995). Phagemid rescue of pBluescript plasmids from purified bacteriophage was performed using the Exassist helper bacteriophage and SolR strain of Escherichia coli, with methods provided by the supplier (Stratagene Cloning Systems). E. coli DH5 $\alpha$ was used for routine plasmid propagation and immunological analysis of expressed Mip. Nucleotide sequencing was done using the Sequenase system (US Biochemical) with the M13 forward and reverse primers, and internal primers synthesized on a Milligen/ Biosearch Cyclone Plus DNA synthesizer. ORFs were identified and translated using the MacVector Sequence Analysis Software (International Biotechnologies). Deduced amino acid sequences were compared with those in the computer databases using the BlastP program available from the National Center for Biotechnology Information (e-mail address: blast@ncbi.nlm. nih.gov). Amino acid sequences were aligned using the 'lineup' program contained in the University of Wisconsin Genetics Computer Group sequence analysis package (Devereux et al., 1984).

Polyacrylamide gel electrophoresis and immunoblotting. Electrophoresis and immunoblotting were performed using described procedures (Rockey \& Rosquist, 1994), with the following modifications. Comparisons of the reactivity of a collection of antisera with a single antigen were conducted using a slot-blotting device (Miniblotter-25, Immunetics). Lysates of GPIC EBs or DH5 $\alpha$ (pGP14.1) were loaded and electrophoresed through preparative $12 \%(\mathrm{w} / \mathrm{v})$ polyacrylamide gels and transferred to nitrocellulose. These filters were placed into a blocking solution consisting of phosphate-buffered saline (PBS, $150 \mathrm{mM} \mathrm{NaCl}, 10 \mathrm{mM}$ sodium phosphate, $\mathrm{pH} 7 \cdot 2$ ) plus $0 \cdot 1 \%$ Tween-20 (TPBS) and $2 \%(\mathrm{w} / \mathrm{v})$ bovine serum albumin (BSATPBS). After blocking, the filters were placed into the slot-blot device. Individual antisera were diluted 1:10 in BSA-TPBS and added to independent slots. After a $2 \mathrm{~h}$ incubation with gentle rocking, blots were washed five times with TPBS using the MF2 washing device (Immunetics), and incubated in ${ }^{125}$ I-protein A (3700-5550 Bq ml ${ }^{-1}$; New England Nuclear) for $1 \mathrm{~h}$. Blots were washed three times in TPBS, dried, and placed in contact with autoradiography film at room temperature for $16 \mathrm{~h}$. To reduce background reactivity in immunoblots using $E$. coli lysates as 
antigen, the antisera were first incubated for $30 \mathrm{~min}$ at room temperature in an equal volume of an E. coli extract (Promega) prior to dilution in BSA-TPBS and incubation with the blot.

Polymerase chain reaction (PCR). PCR was used to amplify relevant regions from genomic DNA of C. psittaci strain B577 and C. trachomatis strain LGV-434. Deoxyribooligonucleotides employed in PCR (Table 1) were derived from the nucleotide sequence of the GPIC genomic DNA insert of pGP14.1, from the published sequence of $C$. trachomatis LGV-434 mip gene (Lundemose et al., 1992), or from the nucleotide sequences generated in these experiments. Amplifications were conducted with Amplitaq DNA polymerase and the 'Hot Start' procedure, using Ampliwax beads, as described by the manufacturer (Perkin-Elmer Cetus). All PCR was performed with a denaturing temperature of $94^{\circ} \mathrm{C}$, an annealing temperature of $50{ }^{\circ} \mathrm{C}$, and a $2 \mathrm{~min}$ extension at $72^{\circ} \mathrm{C}$. Following amplification, reaction products were directly cloned into the pCRII vector (Invitrogen). Plasmids were purified and the ends of the PCR products were sequenced with M13 forward and reverse primers. If needed, internal primers were generated to extend and confirm the resulting sequences. The sequences were translated where appropriate, and compared to the respective GPIC sequences and to those within the computer databases.

(a)

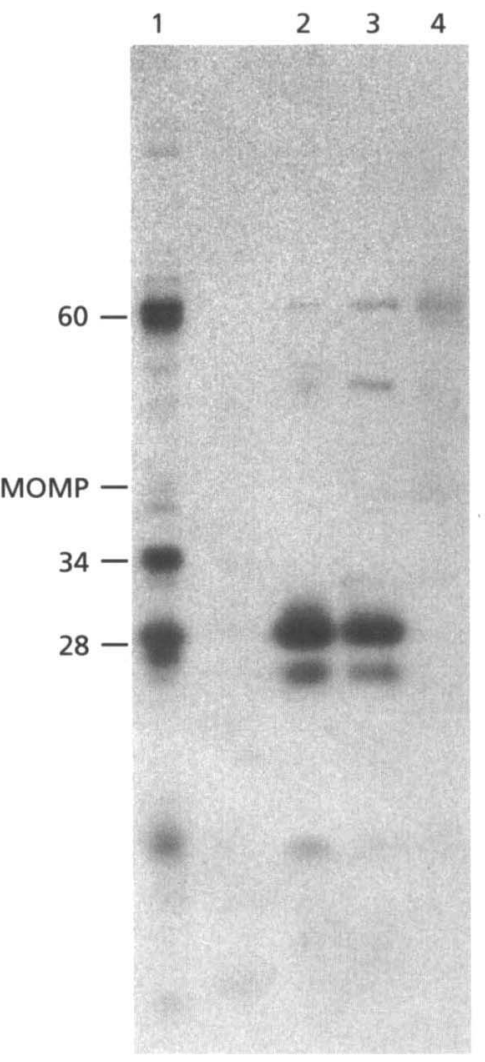

(b)

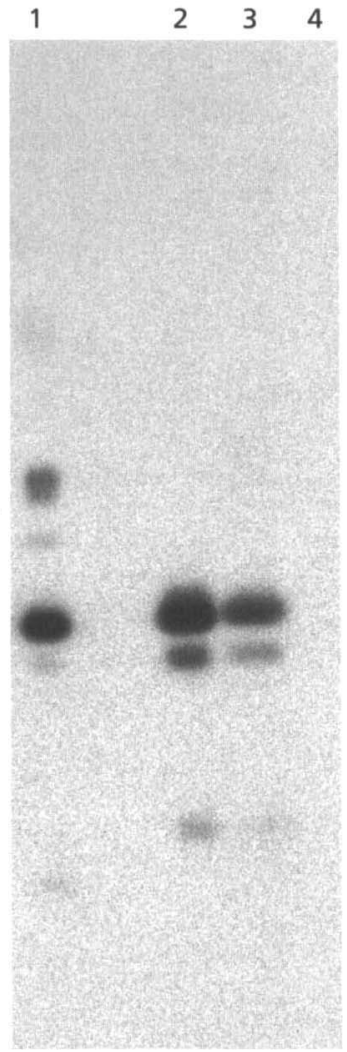

\section{RESULTS}

\section{Recognition of a 28 kDa EB protein by sera from convalescent guinea-pigs}

Immunoblotting with sera from 10 guinea-pigs that had recovered from two serial ocular challenges with GPIC demonstrated that each produced antibodies to several chlamydial antigens, including the previously characterized $39 \mathrm{kDa}$ major outer-membrane protein (MOMP), lipopolysaccharide, and the genus-common $60 \mathrm{kDa}$ antigens (Batteiger \& Rank, 1987; Morrison et al., 1989). Other antigens that were consistently recognized by convalescent animals were a protein of $28 \mathrm{kDa}$ and a group of proteins at approximately $90 \mathrm{kDa}$ (Fig. 1). Convalescent sera from animals that had recovered from a single experimental infection also produced antibodies against this collection of antigens (not shown).

\section{Cloning and sequencing of the C. psittaci mip gene}

To identify the genes coding for the uncharacterized antigens detected in these immunoblots, a genomic expression library of GPIC DNA was constructed in bacteriophage lambda. Screening of this library with convalescent guinea-pig antiserum identified four clones which coded for two uncharacterized $C$. psittaci proteins. Two clones coded for a $39 \mathrm{kDa}$ chlamydial protein (IncA)

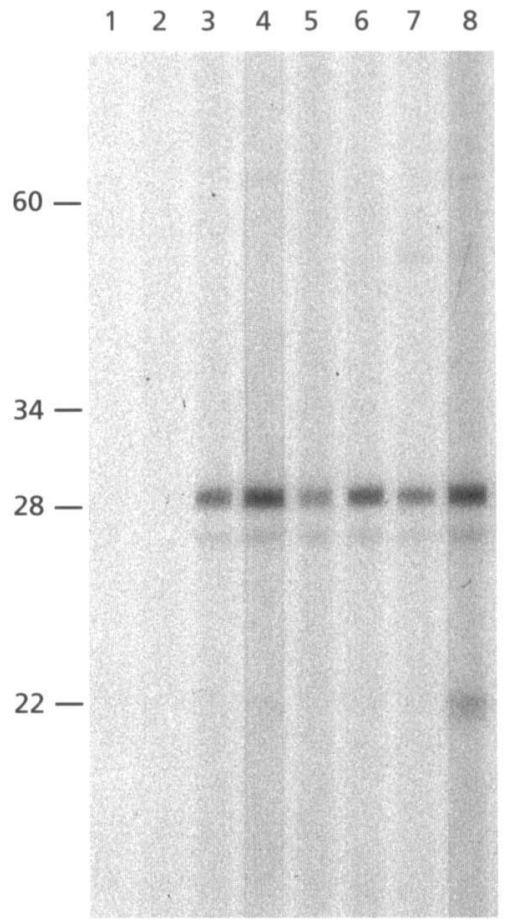

Fig. 3. Preparative immunoblot of $E$. coli $\mathrm{DH} 5 \alpha(\mathrm{pGP} 14.1)$ probed with six individual convalescent sera. Lanes: 1 and 2, preimmune guinea-pig antisera; 3-8, sera from individual guinea-pigs which had recovered from two serial ocular challenges with strain GPIC. Molecular masses are indicated in kDa.
Fig. 2. Immunoblots of lysates of C. psittaci GPIC EBs, and of E. coli DH5 $\alpha$ expressing the $28 \mathrm{kDa}$ GPIC protein. Identical blots were probed with either pooled convalescent sera (a) or serum directed at formalin-fixed GPIC (b). Lanes: 1, GPIC-infected HeLa cells; $2, \mathrm{DH} 5 \alpha(\mathrm{pGP} 14.1) ; 3, \mathrm{DH} 5 \alpha(\mathrm{pGP} 14.2) ; 4$, negative control $E$. coli. The position of MOMP is shown, and molecular masses are indicated in $\mathrm{kDa}$. 


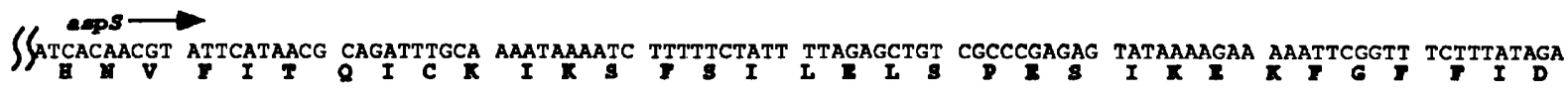

101 TGCTTTAAGT TTTGGTACAC CACCACATTT AGGAATTGCT TTAGGTTTGG ATCGTATTAT GATGGTGTTA ACAGGGGCTG AAGGTATTCG AGAAGTAATA PatI

201 GCTTTCCCGA AAACTCAAAA GGCTGCAGAT TTGATGATGA ATGCGCCTGC GGAAATTATG ACTTCCCAAT TAAAAGAACT AAATATTAAG GTAACTTCTT

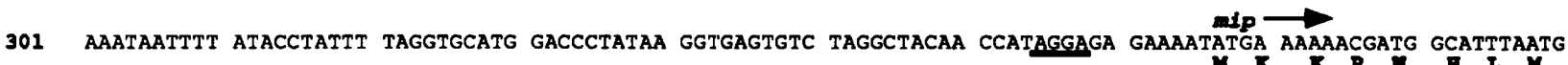

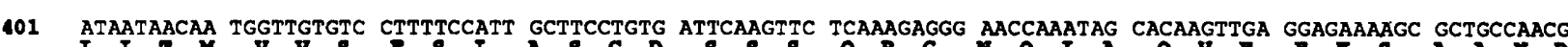

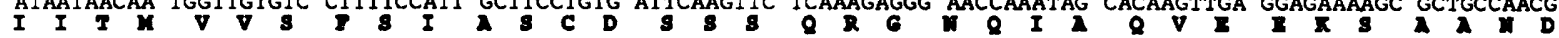

501 ATTCGCAACT TTCTGTAAAT CAACAGATAT CGCGTACTTT CGGTCATTTG CTCGCAAGAC AGTTACGCAA ATCAGAagat ATCATGATGG ATATCGCTGA

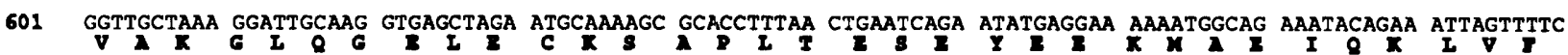

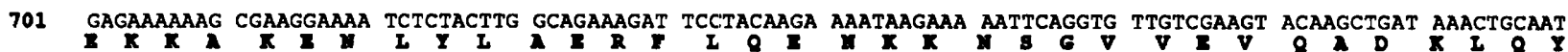

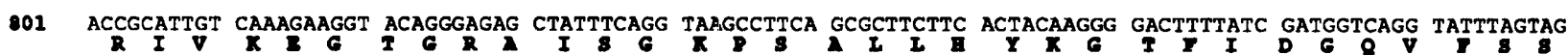

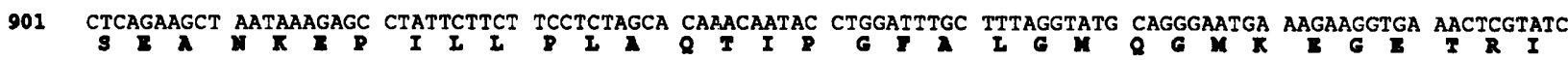

1001 CTTTACATCC ATCCTGATCT TGCTTATGGA ACTTCTGGCC AACTGCCTCC GAACTCTTTA TTGATTTTTG AAATCAATTT AATCGAAACT ACAGATGATT

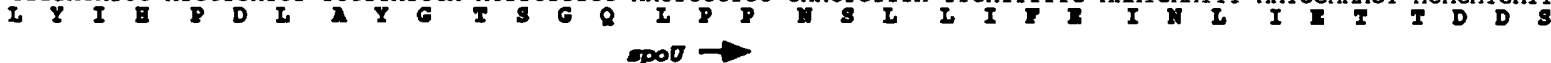

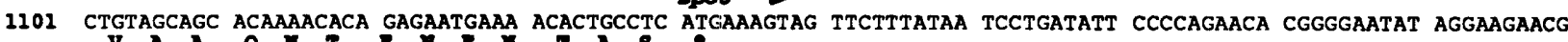

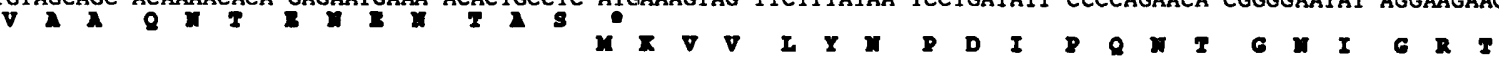

1201 TGTATAGCTC TAGGTGCTGA ATTAATTTTA GTGAGGCCC TAGGGTTTC TTTATTGGAT AAATTTGTTA AGCGCGCAGG GATGGATTAC TGGGATAAGG

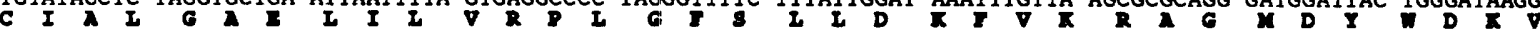
BdodirI

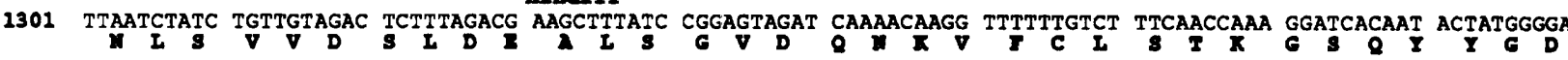

1401 TGTTTCTCTC CCTATGGATG GTGTGTATGT TTTTGGTTCT GAATCAAAAG GATTGCCAGA AGACGTATTA AAGAAATACT ACAACCACTG TTATTACCTA

1501 CCAATGCGGC CTGGTATCAG ATCTTTGAAT TTGGCAACAA CTGTGGGCGT AGTACTTTTT GAAGCAGTTC GACAAAATA TCAAAGTGCT TGTATCCGCA

1601 ATGGGGATTA AGAGTGCTGA TTAATTAACC TAATCAAAGA ATCCTTATCT TTTAGTCCGA CTACACGATC AACCTCTTTC CCATCCTTAA ATAGAATTAG

1701 AGTAGGATT GAAGAAACAC CGTACTGCTC TGCTGGTGCA GGATGGTCAT CTATATTGAC TTTTCCAATA AGCACTGAGG AGACTTCTGC TTCAAGACTT

1801 TCTAATACAG GGGTGAGCAT TTTGCAAGGG CCACACCATT CAGCAAAAAA GTCTATAAGT ACTAGGCCCG TGGCGATGAA GGAATTGAAA TTTTCAGCAG

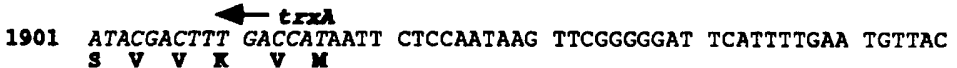

Fig. 4. Nucleotide sequence and the derived amino acid sequence of the GPIC aspS, mip, spoU and trxA genes, encoded by pGP14.1. The aspS sequence is a partial reading frame. The Pstl and HindIII sites that flank the mip coding sequence are indicated, and a possible ribosome-binding site upstream of mip is underlined. Amino acid sequences are indicated in boldface, below the first nucleotide in the codon. The trxA gene is coded by the complementary strand, and is indicated with italics.

which we have recently described (Rockey et al., 1995). The other two clones coded for a $28 \mathrm{kDa}$ protein recognized by both convalescent antisera and sera from guinea-pigs immunized with formalin-fixed EBs (Fig. 2). The rescued pBluescript plasmid clones, designated pGP14.1 and pGP14.2, had inserts of 2.8 and $2.9 \mathrm{kbp}$, respectively, and were shown to be overlapping by restriction endonuclease analyses (not shown). The $28 \mathrm{kDa}$ protein expressed by $\mathrm{DH} 5 \alpha(\mathrm{pGP} 14.1)$ and
(pGP14.2) comigrated precisely with the $28 \mathrm{kDa}$ antigen in the EB lysates (Fig. 2). There were also lower molecular mass antigenic bands in lysates of both GPIC and the recombinant $E$. coli, which may represent common processing products of the $28 \mathrm{kDa}$ protein (Fig. 2, Fig. 3). Additionally, all convalescent sera that recognized the $28 \mathrm{kDa}$ protein in the EB lysates recognized the $28 \mathrm{kDa}$ protein coded by pGP14.1 (Fig. 3). These results support the conclusion that the $28 \mathrm{kDa}$ product coded by plasmids 


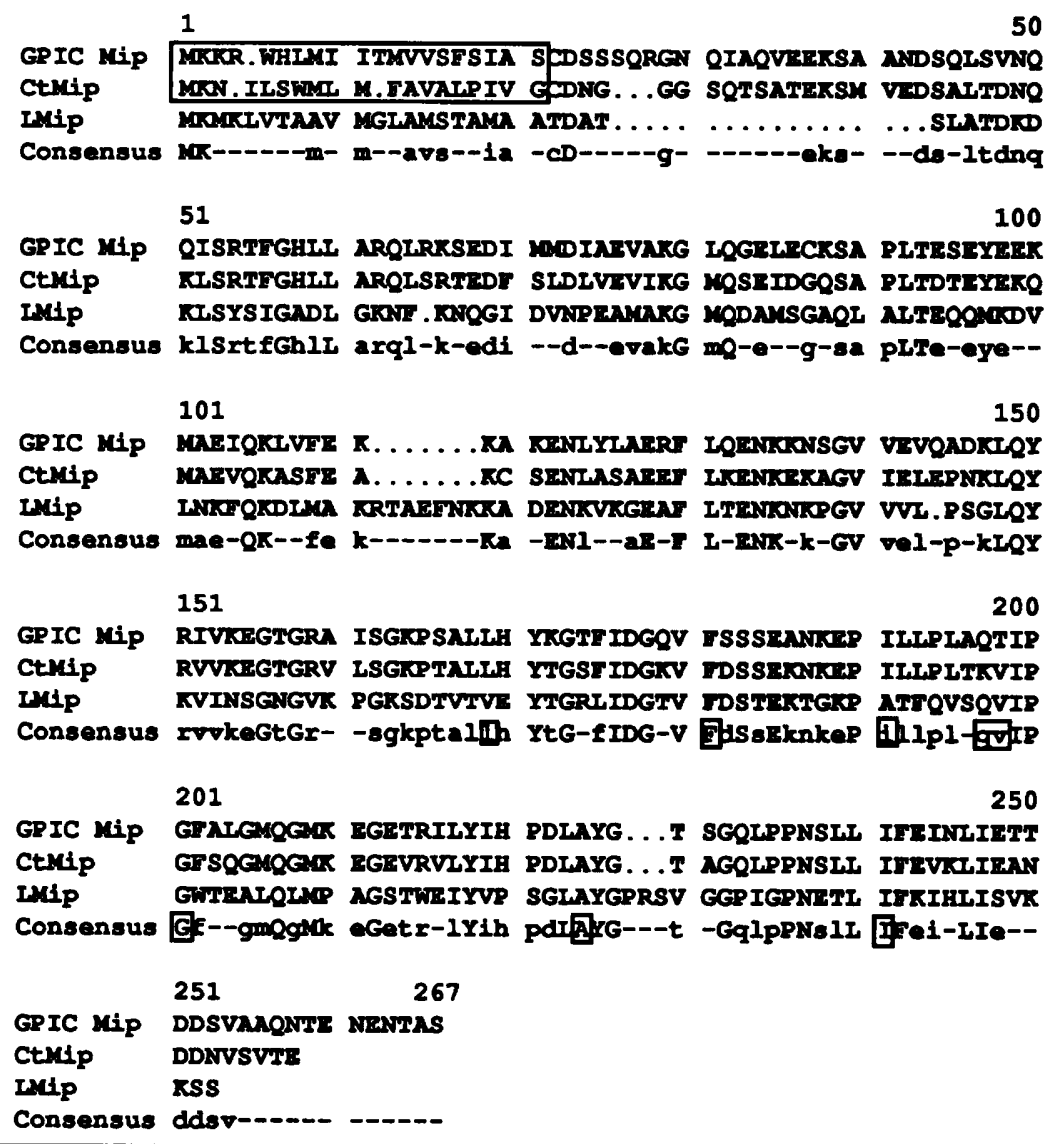

100 


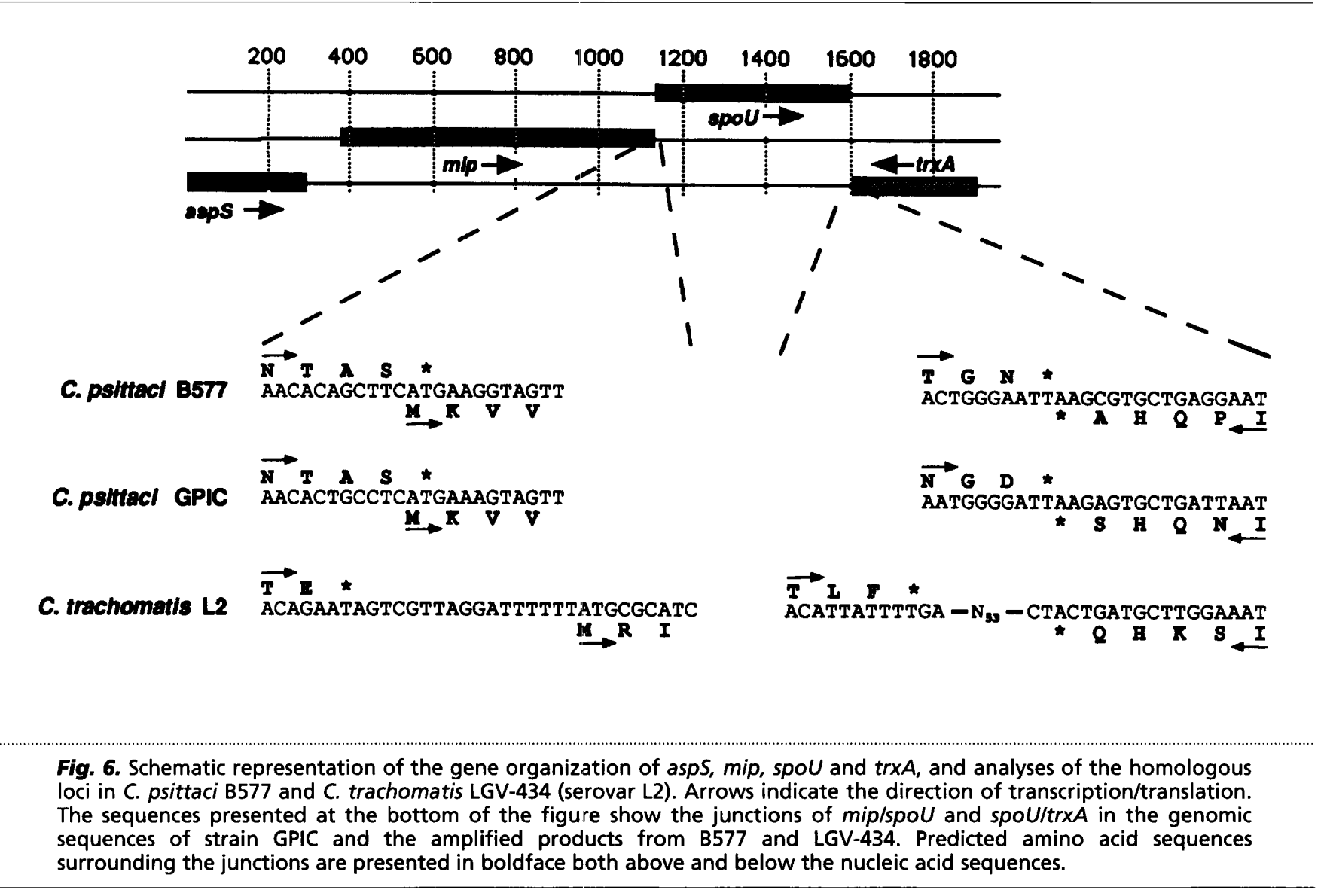

Table 1. PCR oligonucleotides used for the amplification of mip and linked genes from other chlamydiae

A summary of the results using these oligonucleotide pairs with, as template, genomic DNA of C. psittaci strains GPIC and B577, and C. trachomatis serovar LGV-434, is shown.

\begin{tabular}{|c|c|c|c|c|c|c|}
\hline & \multirow{2}{*}{$\begin{array}{c}\text { Region } \\
\text { amplified }\end{array}$} & \multirow[t]{2}{*}{$5^{\prime}$ oligonucleotide } & \multirow[t]{2}{*}{$3^{\prime}$ oligonucleotide } & \multicolumn{3}{|c|}{ Homologous product* } \\
\hline & & & & GPIC & B577 & LGV-434 \\
\hline Pair A & asps/mip & CAACGTATTCATAACG & СTCTTTATTAGCTTCTG & + & + & - \\
\hline Pair B & $m i p / s p o U$ & GAATCCGAATATGAGG & CCATAGGAAGAGCCACGTC & ND & + & - \\
\hline Pair C & $\operatorname{mip} / \operatorname{tr} x A$ & GGAACAGCTGGACAATTACC & TATGGGGGAACCGGTAG & ND & ND & + \\
\hline Pair D & $s p o U / \operatorname{tr} \times A$ & AGGGATGGATTACTG & TATGGGGGAACCGGTAG & + & + & + \\
\hline
\end{tabular}

* An amplification was considered positive if sequence analysis of the cloned PCR product demonstrated that the predicted ORF is contained within the fragment. A negative result indicates that the predicted product was not amplified using these oligonucleotide pairs and the indicated genomic DNA as template. ND, Not determined.

oligonucleotide pairs (Table 1) were used to amplify homologous sequences from genomic DNAs of B577 and LGV-434. The products resulting from these PCR reactions were cloned and sequenced, and the predicted products of ORFs present in these sequences were compared to proteins in the computer databases. The primers used in these experiments and the results of the amplifications are presented in Table 1. PCR reactions were scored as positive if nucleotide sequence analysis of the products identified ORFs with deduced amino acid sequences homologous to those identified in GPIC. These studies demonstrated that the gene organization in B577 was identical to that in GPIC, and that a similar arrangement of mip, spoU and $\operatorname{tr} x A$ was present in $C$. trachomatis LGV-434. We were unable to examine the sequences upstream of mip in LGV-434 because no combination of our primers amplified a product spanning that region. The sequencing also revealed that in the B577 genome both the junction between mip and spoU, and the junction between $s p o U$ and $\operatorname{tr} x A$, have an arrangement of overlapping codons identical to that seen in GPIC (Fig. $6)$. This is distinct from that seen for each of these gene 
junctions in C. trachomatis; the LGV-434 mip and spoU genes are separated by $15 \mathrm{bp}$, while the spoU and $\operatorname{tr} x A$ genes are separated by 53 bp (Fig. 6; Lundemose et al., 1992).

\section{DISCUSSION}

Proteins which bind the immunosuppressant FK506 are present in several different prokaryotic species (reviewed by Hacker \& Fischer, 1993). FKBP are either cytosolic, as with the Neisseria spp., or membrane-associated, as with Legionella spp. and C. trachomatis. Mip-like proteins or mip-like ORFs have also been identified in Coxiella burnetii (Cianciotto et al., 1995), Pseudomonas spp. (Isaki et al., 1990; Konyecsni \& Deretic, 1990), and E. coli (Horne \& Young, 1995). Functionally, LMip is associated with increased infection proficiency by Legionella spp. in several cell types (Cianciotto et al., 1989; Cianciotto \& Fields, 1992), and CtMip may have a role in the early stages of the C. trachomatis infectious process (Lundemose et al., 1993a).

We and others (Batteiger \& Rank, 1987) have previously shown that sera from convalescent guinea-pigs recognize a $28 \mathrm{kDa}$ GPIC protein. Because this protein was highly immunogenic in the context of infection, we pursued its identification and characterization. In this report we have described the cloning of a GPIC DNA fragment coding for a $28 \mathrm{kDa}$ antigenic GPIC protein. Nucleotide sequencing of the insert in plasmid pGP14.1 identified four ORFs, one of which encoded a predicted $28 \mathrm{kDa}$ protein that shared sequence identity with CtMip. The cloned product comigrated with the $28 \mathrm{kDa}$ antigen in lysates of GPIC EB, and all sera that recognized the $28 \mathrm{kDa}$ protein in $\mathrm{EB}$ recognized Mip expressed in E. coli. While other authors have discussed antigenic $28 \mathrm{kDa}$ chlamydial proteins that are not Mip-like proteins (Comanducci et al., 1994), our results support the conclusion that the mip gene described in this work codes for the $28 \mathrm{kDa} \mathrm{EB}$ protein recognized by convalescent guinea-pigs.

These experiments demonstrate that the Mip protein is one of several immunodominant proteins in the guineapig model of chlamydial disease. However, the immune response to chlamydial Mip-like proteins is not likely to be limited to this model system. There are reports in the literature that chlamydial infection of turkeys, mice and sheep stimulates the production of antibodies against a 28-30 kDa protein (Griffiths et al., 1992; Jensen et al., 1990; Pal et al., 1993; Tan et al., 1990). Additionally, humans that have recovered from pneumonia caused by C. pneumoniae produce antibodies against a $30 \mathrm{kDa}$ protein (Puolakkainen et al., 1993; Wilson et al., 1994). While it is not known if each of these species is producing antibodies against Mip-like proteins, it is possible that Mip is a common immunodominant antigen following chlamydial infection.

The mip gene from $C$. trachomatis has been cloned and sequenced from three different serovars. Within this species the sequence is $99 \%$ identical, with only two amino acid differences present in the predicted sequences (Lundemose et al., 1992). The predicted Mip product from C. psittaci is $58 \%$ identical to CtMip and $25 \%$ identical to LMip. During the preparation of this manuscript the sequence of a mip-like gene from Coxiella burnetii, another obligate intracellular bacterial pathogen, was submitted to the GenBank (accession number U14170). The deduced amino acid sequence of $C$. burnetii Mip is $27 \%$ identical to GPIC Mip. Through the region of the protein that encompasses the FK506 binding function (amino acids 169-241) Mip from GPIC and CtMip are $80 \%$ identical, and the GPIC Mip protein is $37 \%$ and $39 \%$ identical to LMip and C. burnetii Mip, respectively.

The mip gene of $C$. psittaci is placed within a cluster of previously unidentified chlamydial genes coding for proteins with diverse functions, including asparagine tRNA ligase (AspS), rRNA methylase (SpoU), and thioredoxin ( $\operatorname{Trx} A)$. The arrangement was conserved among $C$. psittaci strains GPIC and B577, and mip, spoU and $\operatorname{tr} x A$ were shown to be linked in $C$. trachomatis LGV434. It is difficult to propose any functional association among these apparently unrelated gene products or any reason why their genes are juxtaposed in the genome. None of these genes are closely linked in E. coli, although homologues to each have been mapped (Bachmann, 1990; Horne \& Young, 1995; Sharples \& Lloyd, 1991).

While there is no known function in vivo for any prokaryotic FKBP, the presence and possible surface localization of these proteins in several different intracellular pathogens suggests some role for the protein in the intracellular stage of the life cycle. In the eukaryotic cell, cytosolic FK506/FKBP exert their suppressive effects by interfering with calcineurin-mediated regulation of gene activation (Flanagan et al., 1991; Liu et al., 1991). Membrane-associated FKBP of intracellular bacteria may mimic host FKBP and subsequently influence intracellular signalling pathways in order to direct cellular events in favour of the pathogen. Additionally, because this protein is potentially surface-associated and is recognized by infected animals, it may be an important determinant in the immune response against the chlamydiae. Future analyses investigating the immune response to Mip or its function within infected cells are likely to further our understanding of the host-pathogen interaction following chlamydial infection.

\section{ACKNOWLEDGEMENTS}

We are grateful for the editorial assistance of $H$. D. Caldwell and R. J. Belland, and to B. E. Batteiger for sharing information about his work with the guinea-pig antibody response to GPIC. The technical help of Jim Simmons and Janet Sager is greatly appreciated.

\section{REFERENCES}

Bachmann, B. J. (1990). Linkage map of Escherichia coli K-12, edition 8. Microbiol Rev 54, 130-197.

Batteiger, B. E. \& Rank, R. G. (1987). Analysis of the humoral immune response to chlamydial genital infection in guinea-pigs. Infect Immun 55, 1767-1773.

Caldwell, H. D., Kromhout, J. \& Schachter, J. (1981). Purification 
and partial characterization of the major outer membrane protein of Cblamydia trachomatis. Infect Immun 31, 1161-1176.

Chen, N., Zhang, J. \& Paulus, H. (1989). Chromosomal localization of the Bacillus subtilis aspartokinase II gene and nucleotide sequence of the adjacent genes homologous to $u v r C$ and trx of Escherichia coli. J Gen Microbiol 135, 2391-2940.

Cianciotto, N. P. \& Fields, B. S. (1992). Legionella pneumophila mip gene potentiates intracellular infection of protozoa and human macrophages. Proc Natl Acad Sci USA 89, 5188-5191.

Cianciotto, N. P., Eisenstein, B. I., Mody, C. H., Toews, G. B. \& Engleberg, N. C. (1989). A Legionella pneumophila gene encoding a species-specific surface protein potentiates initiation of intracellular infection. Infect Immun 57, 1255-1262.

Cianciotto, N. P., O'Connell, W., Dasch, G. A. \& Mallavia, L. P. (1995). Detection of mip-like sequences and Mip-related proteins within the family Rickettsiae. Curr Microbiol 30, 149-153.

Comanducci, M., Manetti, R., Bini, L., Santucci, A., Pallini, V., Cevenini, R., Sueur, J.-M., Orfila, J. \& Ratti, G. (1994). Humoral immune response to plasmid protein pgp3 in patients with Chlamydia trachomatis infection. Infect Immun 62, 5491-5497.

Devereux, J., Haeberli, P. \& Smithies, O. (1984). A comprehensive set of sequence analysis programs for the VAX. Nucleic Acids Res $12,387-395$.

Engleberg, N. C. \& Eisenstein, B. I. (1991). Progress in the pathogenesis of Legionella pneumopbila. Microb Patbog 10, 11-13.

Engleberg, N. C., Carter, C., Weber, D. R., Cianciotto, N. P. \& Eisenstein, B. I. (1989). DNA sequence of mip, a Legionella pneumophila gene associated with macrophage infectivity. Infect Immun 57, 1263-1270.

Flanagan, W. M., Corthesy, B., Bram, R. J. \& Crabtree, G. R. (1991). Nuclear association of a T-cell transcription factor blocked by FK506 and cyclosporin A. Nature 352, 803-807.

Gold, L., Pribnow, D., Schneider, T., Shinedling, S., Singer, B. S. \& Stormo, G. (1981). Translational initiation in prokaryotes. Annu Rev Microbiol 35, 365-403.

Griffiths, P. C., Philips, H. L., Dawson, M. \& Clarkson, M. J. (1992). Antigenic and morphological differentiation of placental and intestinal isolates of Chlamydia psittaci of ovine origin. Vet Microbiol 30, 165-177.

Hacker, J. \& Fischer, G. (1993). Immunophilins : structure-function relationship and possible role in microbial pathogenicity. Mol Microbiol 10, 445-456.

Horne, S. M. \& Young, K. D. (1995). Escherichia coli and other species of the Enterobacteriaceae encode a protein similar to the family of Mip-like FK506-binding proteins. Arch Microbiol 163, 357-365.

Isaki, L., Beers, R. \& Wu, H. C. (1990). Nucleotide sequence of the Pseudomonas fuorescens signal peptidase II gene $(l s p)$ and flanking genes. J Bacteriol 172, 6512-6517.

Jensen, A. E., Andersen, A. A., Tappe, J. P. \& Thoen, C. O. (1990). Characterization of circulating antibodies against Chlamydia psittaci in turkeys. Avian Dis 34, 878-887.

Konyecsni, W. M. \& Deretic, V. (1990). DNA sequence and expression analysis of alg $P$ and $\operatorname{alg} Q$, components of the multigene system transcriptionally regulating mucoidy in Pseudomonas aeruginosa: algP contains multiple direct repeats. $J$ Bacteriol 172, 2511-2520.

Koonin, E. V. \& Rudd, K. E. (1993). SpoU protein of Escherichia coli belongs to a new family of putative rRNA methylases. Nucleic Acids Res 21, 5519

Liu, J., Farmer, J. D., Jr, Lane, W. S., Friedman, J., Weissman, I. \&
Schreiber,S. L. (1991). Calcineurin is a common target of cyclophilinCyclosporin A and FKBP-FK506 complexes. Cell 66, 807-815.

Lundemose, A. G., Birkelund, S., Fey, S. J., Mose Larsen, P. \& Christiansen, G. (1991). Chlamydia trachomatis contains a protein similar to the Legionella pneumopbila mip gene product. Mol Microbiol $5,109-115$.

Lundemose, A. G., Rouch, D. A., Birkelund, S., Christiansen, G. \& Pearce, J. H. (1992). Chlamydia trachomatis Mip-like protein. Mol Microbiol 6, 2539-2548.

Lundemose, A. G., Kay, J. E. \& Pearce, J. H. (1993a). Chlamydio trachomatis Mip-like protein has peptidyl-prolyl cis/trans isomerase activity that is inhibited by FK506 and rapamycin and is implicated in initiation of chlamydial infection. Mol Microbiol 7, 777-783.

Lundemose, A. G., Rouch, D. A., Penn, C. W. \& Pearce, J. H. (1993b). The Chlamydia trachomatis Mip-like protein is a lipoprotein. J Bacteriol 175, 3669-3671.

Mallinder, P. R., Pritchard, A. \& Moir, A. (1992). Cloning and characterization of a gene from Bacillus stearothermophilus var. nondiastaticus encoding a glycerol dehydrogenase. Gene 110, 9-16.

Monnickendam, M. A., Darougar, S., Treharne, J. D. \& Tilbury, A. M. (1980). Development of chronic conjunctivitis with scarring and pannus, resembling trachoma, in guinea-pigs. $\mathrm{Br} J$ Ophthalmol 64, 284-290.

Morrison, R. P., Lyng, K. \& Caldwell, H. D. (1989). Chlamydial disease pathogenesis. Ocular hypersensitivity elicited by a genusspecific 57-kD protein. $J$ Exp Med 169, 663-675.

O'Connell, W. A., Bangsborg, J. M. \& Cianciotto, N. P. (1995). Characterization of a Legionella micdadei mip mutant. Infect Immun 63, 2840-2845.

Pal, S., Fielder, T. J., Peterson, E. M. \& de la Maza, L. M. (1993). Analysis of the immune response in mice following intrauterine infection with the Chlamydia trachomatis mouse pneumonitis biovar. Infect Immun 61, 772-776.

Puolakkainen, M., Kuo, C. C., Shor, A., Wang, S. P., Grayston, J. T. \& Campbell, L. A. (1993). Serological response to Chlamydia pneumoniae in adults with coronary arterial fatty streaks and fibrolipid plaques. J Clin Microbiol 31, 2212-2214.

Rank, R. G., Batteiger, B. E. \& Soderberg, L. S. F. (1988). Susceptibility to reinfection after a primary chlamydial genital infection. Infect Immun 56, 2243-2249.

Rank, R. G., Batteiger, B. E. \& Soderberg, L. S. F. (1990). Immunization against chlamydial genital infection in guinea-pigs with UVinactivated and viable chlamydiae administered by different routes. Infect Immun 58, 2599-2605.

Rockey, D. D. \& Rosquist, J. L. (1994). Protein antigens of Cblamydia psittaci present in infected cells but not detected in the infectious elementary body. Infect Immun 62, 106-112.

Rockey, D. D., Heinzen, R. A. \& Hackstadt, T. (1995). Cloning and characterization of a Cblamydia psittaci gene coding for a protein localized in the inclusion membrane of infected cells. Mol Microbiol $15,617-626$.

Sharples, G. J. \& Lloyd, R. G. (1991). Location of a mutation in the aspartyl-tRNA synthetase gene of Escherichia coli K12. Mutat Res 264, 93-96.

Tan, T.-W., Herring, A. J., Anderson, I. E. \& Jones, G. E. (1990). Protection of sheep against Chlamydia psittaci infection with a subcellular vaccine containing the major outer membrane protein. Infect Immun 58, 3101-3108.

Treharne, J. D. \& Shallal, A. (1991). The antigenic specificity of the humoral immune response to primary and repeated ocular infections of the guinea-pig with the GPIC agent (Chlamydia psittaci). Eye 5, 299-304. 
Watkins, N. G., Hadlow, W. J., Moos, A. B. \& Caldwell, H. D. (1986). Ocular delayed hypersensitivity: a pathogenetic mechanism of chlamydial conjunctivitis in guinea-pigs. Proc Natl Acad Sci US A 83, 7480-7484.

Wilson, P. A., Phipps, J. \& Treharne, J. D. (1994). Antigenic specificity of the humoral immune response to infection by $C$. pneumoniae. In Chlamydial Infections, pp. 177-180. Edited by J. Orfila and others. Bologna: Societa Editrece Esculapio.

Received 10 July 1995; revised 4 October 1995; accepted 15 November 1995. 